\title{
Comparative clinical evaluation of efficacy and safety of a formulation containing ciclopirox $8 \%$ in the form of a therapeutic nail lacquer in two different posologies for the treatment of onychomycosis of the toes
}

\author{
Avaliação clínica comparativa da eficácia e da segurança de formulação \\ contendo ciclopirox a $8 \%$ na forma de esmalte terapêutico em duas diferentes \\ posologias no tratamento de onicomicoses dos pododáctilos
}

Sergio Schalka ${ }^{1}$

Samanta Nunes ${ }^{2}$

Antonio Gomes Neto

\begin{abstract}
BACKGROUND: The use of topical antifungal agents in the treatment of onychomycosis is of great value in clinical practice as there are different limitations regarding the use of systemic treatment.

OвJестіve - To evaluate the efficacy and safety of a nail lacquer formulation containing ciclopirox $8 \%$ in two different posologies: the traditional regimen (3/2/1) and a regimen of weekly use.

METHODS - A blind, randomized, comparative trial which included 41 patients divided into 02 groups, with Group I using the nail lacquer once weekly and Group II using the traditional regimen (3/2/1). Both groups applied the medication for 06 months.

ReSUlTS - The species most frequently found in groups I and II were Trichophyton rubrum (55\% and 61.9\%) and Trichophyton mentagrophytes (30\% and 19\%). There was a tendency to a higher level of treatment resistance by T. mentagrophytes infection in both groups, without any predilection for sex, age, proportion of the nail affected at the beginning of the study, duration of the clinical disease and quantity of nails affected per person. Both groups had significant levels of mycological cure, clinical response and therapeutic success and there was no statistically significant difference between groups I and II ( $\mathrm{p}>0.05)$.

CONCLUSION: The nail lacquer containing ciclopirox $8 \%$ was equally effective at a weekly dose when compared to the traditional dosing (3/2/1), allowing a more comfortable regimen.
\end{abstract}

Keywords: Administration, topical; Nail diseases; Onychomycosis; Posology; Therapeutics

Resumo: Fundamentos: A utilização de antifúngicos tópicos na terapêutica da onicomicose é de grande valor na prática clínica, visto que há diferentes limitações ao uso das opções terapêuticas sistêmicas.

OBjetrvo: Avaliar comparativamente a eficácia e a segurança de uma formulação de esmalte de ciclopirox a 8\% em dois diferentes esquemas posológicos: o esquema tradicional (3/2/1) e um esquema posológico de uso semanal.

MÉTodos: Foi realizado um estudo cego, comparativo e randomizado que incluiu 41 pacientes, divididos em dois grupos, sendo o grupo I submetido ao esquema posológico de uma vez por semana e o grupo II submetido ao esquema posológico tradicional (3/2/1). Os grupos utilizaram a medicação por 180 dias.

RESULTADOS: As espécies mais frequentemente encontradas nos grupos I e II foram Trichophyton rubrum (55\% e 61,9\%) e Trichophyton mentagrophytes (30\% e 19\%). Houve tendência de maior resistência ao tratamento pelo T. mentagrophytes nos dois grupos estudados, sem predileção por sexo, idade, proporção de acometimento ungueal inicial, tempo de evolução do quadro ou número de unhas acometidas por indivíduo. Ambas as modalidades apresentaram índices significativos de cura micológica, resposta clínica e sucesso terapêutico, e não houve diferença estatisticamente significante entre os grupos I e II ( $\mathrm{p}>0,05)$.

CONCLUSÃO: O esmalte contendo ciclopirox a $8 \%$ mostrou-se igualmente eficaz na posologia de uma vez por semana quando comparada à posologia tradicional (3/2/1), permitindo um esquema posológico mais confortável.

Palavras-chave: Administração tópica; Doenças da unha; Onicomicose; Posologia; Terapêutica

Received on 15.12 .09

Approved by the Advisory Board and accepted for publication on 22.01.11

* Work performed in a private clinic - Osasco (SP), Brasil.

Conflict of interest / Conflito de interesse: Schalka S received grants for the performing of the study, which was sponsored by Theraskin Laboratory, where he

also works as a speaker. Nunes S and Gomes A are consulting doctors of the Theraskin company.

Financial funding / Suporte financeiro: Theraskin Farmacêutica Ltda.

Physician, Dermatologist - Master in Dermatology by the Medical School of the Universidade de São Paulo (FMUSP) - São Paulo (SP), Brasil.

Physician, Dermatologist - Private Clinic - São Paulo (SP), Brasil.

Physician, Dermatologist - Private Clinic - Campinas (SP), Brasil.

(C)2012 by Anais Brasileiros de Dermatologia 


\section{INTRODUCTION}

Onychomycosis is one of the most common illnesses in dermatology and its cause is associated with a fungus of the following group: dermatophyte, nondermatophyte and yeast. ${ }^{1,2,3}$ They involve the toenails in $80 \%$ of the cases, and the species with the highest prevalence is the Trichophyton rubrum. The incidence is higher in countries with warm and humid climate, characteristic of tropical areas. ${ }^{4,5}$ The distribution also varies according to populational aspects like: sex, age, immunity (higher incidence in immunocompromised); and behavior (social, cultural, religious and economic). ${ }^{5}$

It develops most commonly in individuals with other nail abnormalities (ex. history of nail trauma), in immunocompromised patients (for example, with diabetes mellitus, HIV infected or individuals who use immunosuppressant), individuals with peripheric vascular insufficiency and children with Down syndrome. ${ }^{4}$

Onychomycosis can be clinically classified in 04 specific types:

Distal subungual onychomycosis, the most common clinical variety, in $90 \%$ of the cases;

White superficial onychomycosis, present in only $5 \%$ of the cases, with higher incidence in children;

Proximal subungual onychomycosis, the least common clinical variety, usually associated with patients with the acquired immunodeficiency syndrome; ${ }^{6}$

Total onychodystrophy: the most severe form of onychomycosis.

The subungual onychomycosis involves the distal nail bed, the nail plate and the eponychium. The infection usually starts from tinea pedis from neighboring areas and the most common form is the distal lateral subungual onychomycosis. On the proximal subungual onychomycosis the fungus usually invades the nail apparatus through the proximal nail fold. Immunosuppressant conditions must be investigated. The white superficial form of onychomycosis is less common. In this form the nail takes a whitish appearance, like chalk, sometimes with white islets on the nail plate. The fungus most commonly responsible for this clinical form is the Trichophyton mentagropbytes, but non-dermatophyte fungus can also cause it (like Aspergillus, Fusarium and others). On the total dystrophic variety of onychomycosis there is a complete destruction of the nail, which is thickened and loses its normal architecture. T. rubrum is the most common causative agent of this variety, followed by $T$ mentagrophytes. Other dermatophytes, like E. floccosum, T. tonsurans, Microsporum canis, T violaceum, are isolated in cultures less frequently.

The clinical characteristics of dystrophic nails should alert to the possibility of the diagnosis of onychomycosis. The most frequent differential diagnoses are: chronic nail trauma, ungual psoriasis and ungual lichen planus.

The involvement of the nail by the fungus happens via the penetration of the pathogenic agent through the distal margin, lateral margins or surface of the nails, and the diagnosis is defined by the direct mycological examination (DME) under clarification with potassium hydroxide $(\mathrm{KOH})$ and culture for fungus, in many cases making it possible the identification of the species. Other exams that can also be used are biopsy of the nail plate and dying with Periodic Acid Schiff (PAS) and, less frequently, immunohistochemistry and even polymerase chain reaction (PCR) essays. ${ }^{4,7}$

The treatment is sometimes problematic, it takes a long time and the dosage regimens are not always practical, which results in inefficiency of the treatment with relapsing of the condition. The situation is even more serious in elderly patients, who quite often have associated morbid conditions that preclude the use of systemic medications. In this case the topic therapeutic is extremely valuable.

The most illustrative study of the efficacy of the topical therapeutic was conducted by Bohn and Kraemer in 2000, where the dermatologic-pharmacology of ciclopirox in nail lacquer was established. ${ }^{8}$

Systemic antifungal agents, terbinafine, itraconazole or fluconazole will reach the nail bed and the nail matrix via the blood flow. In this case the drug is distributed from the ventral to the dorsal, and from the proximal to the distal areas. Although it is expected that the concentration of the drug on the nail plate is higher during treatment, the drug can be recovered from nail cuts for up to 6 to 12 months after the end of the treatment. ${ }^{5}$ On the other hand, when a therapeutic lacquer is applied on the dorsum of the nail plate the drug crosses the dorsal to the ventral area. Previous studies have demonstrated that the ciclopirox olamine had a penetration of $0,4 \mathrm{~mm}$ into the nail bed after only one application. ${ }^{8}$

Ciclopirox and its salt, ciclopiroxolamine, are hydroxypiridones that are chemically and mechanically different from other antifungal agents on the market, like the azolic derivates and alilamines. Unlike most currently available antifungal agents, ciclopirox does not affect the biosynthesis of the sterols and it is metabolized via cytochromo $\mathrm{P} 450$. The antifungal action of the ciclopirox involves the chelating of the polyvalent cat ions (like $\mathrm{Fe}^{3+}$ ), inhibiting the enzymes responsible for the degradation of the toxic peroxides on the fungal cell. ${ }^{9}$

Ciclopirox has a vast antifungal spectrum and it is efficient against the principal pathogenic fungus responsible for the onychomycosis. It has in vitro fun- 
gicide effect against strains of T. rubrum, T. mentagrophytes and Epidermophyton floccosum, the fungal species that usually cause onychomycosis. In vitro ciclopirox is equally efficient against Candida $s p$ and non-dermatophyte filamentous fungus, for example, Scopulariopsis brevicaulis, Aspergillus $s p$ and Scytalidium byalinum.

In terms of the topical treatment of the onychomycosis the facts that contribute to the efficacy of the treatment include long term contact between the drug and the nail plate and the evaporation of the solvents, which leads to an increment of the concentration of the ciclopirox from $8 \%$ to $34,8 \%$ on the residual film over the nail plate. ${ }^{10}$ One of the facts that are still a challenge in terms of increasing the efficacy rates of the topical treatment, or even reduce its posology, is the introduction of substances that increase the penetration of the active components already known to be efficient.

The nail plate contains much less lipids than the horned layer of the skin and also a reduced capacity to absorb water and other materials. The nail can react in a different manner in the presence of promoters of penetration. The nail plate represents less than $1 \%$ fat when compared to the approximately $10 \%$ or more lipids present on the stratum corneum. ${ }^{11}$

It is believed that the distribution and the concentration of lipids on the human nail plate can affect the permeation of drugs. The classification order of the total lipids in each layer is: ventral layer $>$ dorsal layer $>$ intermediate layer. The dorsal layer is characterized by a low diffusivity of drugs, the intermediate layer is characterized by low lipophilicity and the ventral layer is characterized by high lipophilicity. ${ }^{11}$

The substances commonly used for the extraction of the lipids and higher penetration of the active substances on the skin and stratum corneum are not useful to increase the penetration on the nail plate. An agent mildly soluble in water is not capable of staying at high concentration on the nail plate.

The use of an agent capable of amplifying the penetration of the antifungal active substance on the nail plate would potentiate the antifungal effect of this substance and this way, would permit a more comfortable dosage regimen.

The objective of this study was to evaluate the efficacy and safety of a nail lacquer formulation of ciclopirox olamine at $8 \%$, comparing two different posologic regimens.

\section{MATERIAL AND METHODS}

Previous to the commencement of the study the protocol was analyzed and approved by the Research Ethics Committee (REC).

41 volunteers from both sexes were selected and subsequently included in the study. The age varied from 18 to 65 years and they presented with distal or lateral subungual onychomycosis of the $1^{\text {st }}$ right or left toe. Only onychomycosis involving between 10 and $50 \%$ of the nail plate and without matrix involvement were included. The Free and Explained Consent Form was read and signed by all the volunteers, prior to the commencement of the study.

All the patients were submitted to direct mycological examination and culture for dermatophytes and/or yeasts before the beginning of the study. Only when the positivity of the exam and the patients' eligibility were confirmed they were entered into the study. ${ }^{12}$

An initial assessment questionnaire was filled in by the principal investigator and the nail in each individual that would serve as the parameter for the evaluation of the treatment was defined (nail of the first right or left toe), and this nail was subsequently measured in terms of: total extension of the nail (T) and extension of the non-involved or healthy nail $(\mathrm{H})$. After this evaluation the patients were randomly assigned to one of two groups, in a single blind form:

- Group I : Ciclopirox nail lacquer on the posology of once a week for 6 months.

- Group II : Ciclopirox nail lacquer on the posology of three times a week on the first month, two times a week on the second month and once a week till the end of the sixth month (regimen named 3/2/1).

Further on the volunteers received the samples and orientations of how to use them.

Both groups applied the ciclopirox nail lacquer in all the affected nails, each group following the previously established posologic regimen.

During the whole study dermatologic evaluations were performed with 60 and 120 days of using the ciclopirox nail lacquer, when the patients were submitted to new clinical examinations with measures of the extension of the non-involved or healthy nail (respectively $\mathrm{H}_{1}$ and $\mathrm{H}_{2}$ ).

At the end of 180 days of use the patients were again evaluated and submitted to a final measure of the nail $\left(\mathrm{H}_{3}\right)$. After 15 days after the interruption of the treatment (wash out period), samples of the nail were collected for cultivation of the fungus and verification of the mycologic cure.

The primary efficacy variable was the therapeutic success, defined as negative culture and clinical improvement equal to or higher than $90 \%$ of the healthy nail. The secondary efficacy variable was the mycologic cure (negative culture) and clinical improvement, meaning negative culture and improvement between $50 \%$ and $90 \%$ of the affected nail, and the percentage of improvement of the extension of the affected nail. The secondary objective of the study was 
to evaluate the safety of these formulations and their potential adverse effects.

The percentage of improvement of the extension of the affected nail was defined by

$\left(\mathrm{H}_{\mathrm{i}}-\mathrm{H}_{0}\right) /\left(\mathrm{T}-\mathrm{H}_{0}\right) * 100$, where $\mathrm{H}_{\mathrm{i}}$ is the extension of the healthy nail on visit $i, i=1$ (60 days), 2 (120 days) or 3 (180 days), $\mathrm{H}_{0}$ is the extension of the healthy nail on the baseline visit and $\mathrm{T}$ is the total extension of the nail (Figure 1).

\section{STATISTICAL ANALYSIS}

The exact Fisher test was used to compare the proportions of responses to the classificatory variables. The longitudinal profiles of the percentage of improvement of the extension of the affected nail along the study were compared using a mixed linear model for repetitive measures and the restricted maximum verisimilitude. The terms fixed visit, treatment group and interaction visit by treatment group were included on the model. Volunteer was included on the model as random factor. Time of progression of the disease, number of affected nails at the beginning of the treatment and proportion of affected nail at the beginning of the study were considered as co-variables on the model. The analysis of residues did not indicate the need for transformation of the variable response. The SAS v8.2 system was used to process the statistical analysis.

\section{RESULTS}

41 patients completed the study, 20 on group I and 21 on group II.

Amongst the 20 patients allocated to group I and 21 to group II, $75 \%$ and $95 \%$ were female, respectively. The average age on both groups was the same (41,2 years), varying between 18 and 63 years on group I (median: 39 years) and between 19 and 65

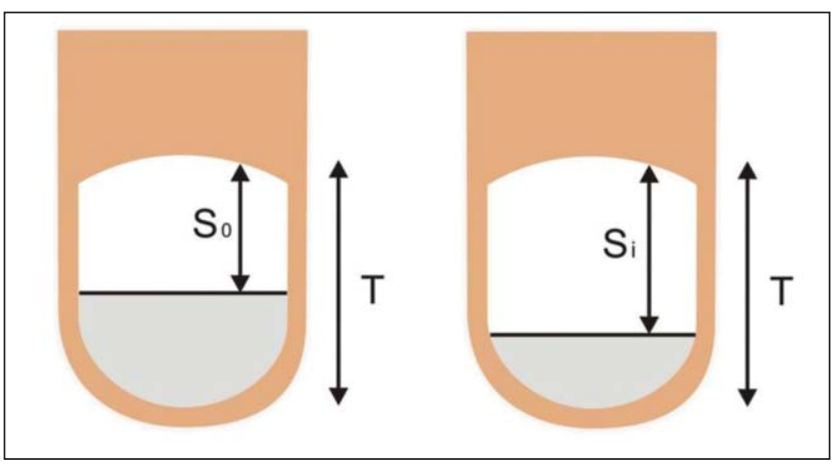

Figure 1: Illustration of the method used to measure the area of affected nail. On the left, $\mathrm{S}_{0}$ represents the extension of healthy nail at the beginning of the study and $T$ the total extension of the nail. On the right, $S_{i}$ represents the extension of healthy nail along the visits (60,120 and 180 days) and $\mathrm{T}$ the total extension of the nail. The greyish area represents the ungual extension affected by the fungus years on group II (median: 40 years).

Descriptive statistics of demographic and baseline assessments of the treatment groups are presented on an informative basis in order to characterize the target population, and the non dependant comparison of the treatments was confirmed by randomization (Tables 1 to 4). ${ }^{13,14}$ The presence of fungus on the baseline evaluation was similar in both treatment groups.

When analyzing the genus and species most frequently found, there was a predominance of the Trichophyton genus, the Trichophyton rubrum and Trichophyton mentagrophytes being represented, respectively, in $55,0 \%$ and $30 \%$ of the subjects that used the posology of once a week (group I), and in 61,9\% and $19 \%$ of the subjects of the 3/2/1 regimen (group II). The other species identified were Scytalidium dimidiatum and Candida albicans with a frequency of less than $10 \%$. At the beginning of the study a predilection of any fungal species was not observed on the individual characteristics analyzed: sex, age, number of involved nails, time of evolvement of the onychomycosis, percentage of involved nail, previous treatments and type of involvement by the onychomycosis.

\section{Safety Evaluation}

None of the 41 patients that started the study had any adverse effect during the study period, either on the treated area or systemic.

\section{Efficacy Evaluation}

\section{1-Primary Efficacy Variable}

Therapeutic Success

There was no significant difference between the treatment groups, according to the Fisher exact test, in terms of therapeutic success, proportion of patients with negative culture and more than $90 \%$ of healthy nail at the end of the study $(p=0,89)$.

\section{2-Secondary Efficacy Variable}

Mycological Cure

There was no significant difference between the

TABLE 1: Type of ungual involvement by group

\begin{tabular}{llll}
\hline $\begin{array}{l}\text { Treatment } \\
\text { Group }\end{array}$ & \multicolumn{2}{c}{ Type of Onychomycosis } & \multirow{2}{*}{ Total } \\
\cline { 2 - 3 } & $\begin{array}{l}\text { Distal } \\
\text { sub ungueal }\end{array}$ & $\begin{array}{l}\text { Lateral } \\
\text { sub ungueal }\end{array}$ \\
\hline I & $9(45 \%)$ & $11(55 \%)$ & 20 \\
II & $14(66,67 \%)$ & $7(33,33 \%)$ & 21 \\
& & & \\
\hline
\end{tabular}


TABLE 2: Proportion of affected nail

\begin{tabular}{|c|c|c|c|c|c|c|}
\hline Treatment Group & $\mathbf{N}$ & Average & Standard Deviation & Highest Value & Median & Lowest Value \\
\hline I & 20 & $40 \%$ & $10 \%$ & $56,25 \%$ & $44,15 \%$ & $14,28 \%$ \\
\hline II & 21 & $40 \%$ & $10 \%$ & $53,85 \%$ & $47,05 \%$ & $25 \%$ \\
\hline
\end{tabular}

TABLE 3: Time of evolution of the onychomycosis (months)

\begin{tabular}{lllllll}
\hline Treatment Group & N & Average & Standard Deviation & Highest Value & Median & Lowest Value \\
\hline I & 20 & 22,3 & 26,7 & 120 & 12 & 6 \\
II & 21 & 18,2 & 17,5 & 84 & 12 & 3 \\
\hline
\end{tabular}

treatment groups, according to the Fisher exact test, in terms of mycological cure and proportion of patients with negative culture at the end of the study $(\mathrm{p}=0,92)$.

Amongst the cases with positive culture after the end of the study, $100 \%$ were identified as from the Trichophyton genus, the mentagrophytes species with a higher tendency to resistance. On group I there was persistence of positive culture in $18 \%$ of the conditions caused by T. rubrum and $66 \%$ of those caused by T. mentagrophytes. On group II, 30\% of the cases by $T$. rubrum and $50 \%$ of those caused by T. mentagrophytes remained with positive culture for fungus at the end of the study.

A preference of the cases that persisted with positive culture at the end of the study was not observed in terms of the individual parameters evaluated: sex, age, number of involved nails, time of evolvement of the onychomycosis, percentage of involved nail, previous treatments and type of involvement by the onychomycosis.

\section{Clinical Improvement}

There was no significant difference between the treatment groups, according to the Fisher exact test, in terms of clinical improvement, proportion of patients at the end of the study with negative culture and improvement of the affected nail of more than $50 \%$ in

TABle 4: Percentage of affected nail at the beginning of the treatment

\begin{tabular}{lll}
\hline \multirow{2}{*}{$\begin{array}{l}\text { Percentage of } \\
\text { Affected Nail }\end{array}$} & \multicolumn{2}{l}{ Treatment Group } \\
& I & II \\
\hline $10 \mid--20$ & $2(10 \%)$ & $0(0 \%)$ \\
$20 \mid--30$ & $1(5 \%)$ & $1(4,76 \%)$ \\
$30 \mid--40$ & $5(25 \%)$ & $4(19,05 \%)$ \\
$40 \mid--50$ & $12(60 \%)$ & $16(76,19 \%)$ \\
\hline
\end{tabular}

relation to the start of the treatment $(p=0,88)$.

Percentage of Improvement of the Extension of the Affected Nail

The interaction between Group and Visit is not significant ( $\mathrm{p}=0,1775$; Table 5 ). There is no significant difference of the longitudinal profiles of percentage of improvement of the extension of the affected nail between the treatment groups, along the visits $(p=0,6309 ;$ Table 5). There was a statistically significant improvement of the percentage of improvement of the extension of the affected nail along the 180 days of treatment on both treatment ( $p<0,0001$; Table 5). Groups I and II showed, on average, at the end of the treatment, around $80 \%$ of improvement (Table 6 and Graph1). The co-variables evolution time, number of affected nails and proportion of affected nails in $V_{0}$ were not statistically significant to explain the variability of the percentage of improvement (Table 5).

\section{DISCUSSION}

Many adults suffer with chronic infection of the nails. Around $18 \%$ of the world population has a microbial infection of the nail plate. The prevalence of the disease increases with advancing age and it is suggested that up to $50 \%$ of the population over 70 years is affected. ${ }^{15}$ These infections can be a problem in patients with compromised peripheric circulation, elderly and diabetics, not only because of the complications related to chronic infections, but also due to the limitations to the use of systemic antifungal agents for a long time. In these cases the option of a topical treatment is valuable.

The use of nail lacquers as a topical therapeutic option in the treatment of mild and moderate onychomycosis has shown very expressive results, especially if we consider their efficacy, low toxicity and comfortable posologic regimen, when compared to systemic treatment.

There is relative consensus on the indication of 
TABLE 5: Fixed effects tests for reduction of the affected nail

\begin{tabular}{lllll}
\hline Effect & Num GL & Den GL & Value de F & Pr $>$ F \\
\hline Group & 1 & 36 & 0.23 & 0.6309 \\
Visit & 2 & 78 & 152.37 & $<.0001$ \\
Group*Visit & 2 & 78 & 1.77 & 0.1775 \\
Evolution Time & 1 & 36 & 1.70 & 0.2002 \\
Number of Affected Nails & 1 & 36 & 0.71 & 0.4058 \\
Proportion of affected nail at $\mathrm{V}_{0}$ & 1 & 36 & 0.01 & 0.9040 \\
\hline
\end{tabular}

TABLE 6: Percentage of reduction of the area of affected nail by treatment group and visit

\begin{tabular}{|c|c|c|c|c|c|c|c|}
\hline $\begin{array}{l}\text { Treatment } \\
\text { Group }\end{array}$ & $\begin{array}{l}\text { Treatment } \\
\text { Days }\end{array}$ & $\mathbf{N}$ & Average & $\begin{array}{l}\text { Standard } \\
\text { Deviation }\end{array}$ & $\begin{array}{l}\text { Highest } \\
\text { Value }\end{array}$ & Median & $\begin{array}{l}\text { Lowest } \\
\text { Value }\end{array}$ \\
\hline \multirow[t]{3}{*}{ I } & 60 & 20 & $23,2 \%$ & $16,4 \%$ & $50 \%$ & $23,6 \%$ & $0 \%$ \\
\hline & 120 & 20 & $61,7 \%$ & $29,1 \%$ & $100 \%$ & $55 \%$ & $0 \%$ \\
\hline & 180 & 20 & $82,5 \%$ & $14 \%$ & $100 \%$ & $85,7 \%$ & $44 \%$ \\
\hline \multirow[t]{3}{*}{ II } & 60 & 21 & $27,9 \%$ & $16,9 \%$ & $71,4 \%$ & $25 \%$ & $0 \%$ \\
\hline & 120 & 21 & $58,7 \%$ & $17,7 \%$ & $95 \%$ & $62,5 \%$ & $22,8 \%$ \\
\hline & 180 & 21 & $75,7 \%$ & $15,7 \%$ & $100 \%$ & $78,6 \%$ & $46,2 \%$ \\
\hline
\end{tabular}

topical therapeutic in the treatment of onychomycosis without involvement of the nail matrix and with involvement of less than $50 \%$ of the distal nail plate.

The ciclopiroxolamine was introduced for the first time on the market in April 1975, and currently it is commercialized in more than 70 countries. The nail lacquer presentation was initially approved in France in 1991. Since then the product has been approved for use in more than 40 countries, and in the United States it was the first non-oral agent approved for the management of onychomycosis, in December 1999.

The posology initially suggested of the ciclopiroxolamine $8 \%$ nail lacquer was a daily application, subsequently approved for use following the regressi- ve regimen: 3 times a week on the first month, twice a week on the second month and once a week from the third to the sixth and last month, what we called $3 / 2 / 1$ regimen. $^{16}$

However, despite being safer than the systemic therapeutic option, the posologic regimen is still not comfortable.

The present study assessed, in a comparative way, the two posologic regimens described above for this formulation of a nail lacquer containing ciclopirox at $8 \%$.

When analyzing the results in terms of the population evaluated we noticed a homogeneous distribution between the two groups, in terms of sex,

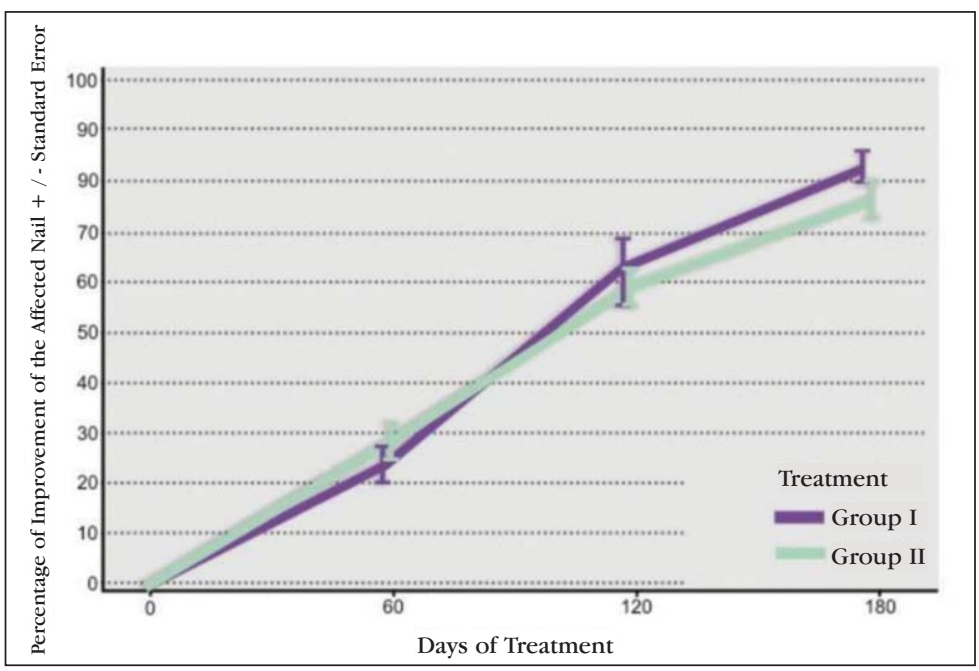

GRAPH 1: Percentage of improvement of the affected nail along the visits, by treatment group 
age, involved area, proportion of affected nail, time of evolution and previous treatments, this way reducing the interference of these characteristics on the interpretation of the results.

During the analysis of the efficacy variables we observed that both the Therapeutic Success (primary efficacy variable) and Mycological Cure and Clinical Improvement (secondary efficacy variable) did not show any statistically significant difference between groups I and II, demonstrating that the posology of once a week has similar results to the most commonly used posology of ciclopirox (3 times a week on the first month, twice a week on the second month and once a week from then on).

When comparing these numbers with previously performed studies we observed that the results are similar in terms of: Therapeutic Success ( $45 \%$ on group I and $42,86 \%$ on group II), Mycological Cure ( $70 \%$ on group I and $71,43 \%$ on group II) and Clinical Improvement ( $50 \%$ on group I and $52,38 \%$ on group
II) (Table 7). We might also consider as a positive result the value of $80 \%$ for the improvement of the extension of the affected nail, a value similar to data from the literature (Graph 1). ${ }^{15-17}$

The statistical analysis shows that there was no significant difference between the two posologic regimens in both the clinical and mycological evaluations.

We understand that both posologic options offer the same efficacy on the control of toe onychomycosis and, therefore, the weekly therapeutic regimen is a more adequate therapeutic option due to the posologic convenience it allows.

\section{CONCLUSION}

The ciclopirox $8 \%$ nail lacquer formulation was safe and efficient in the clinical treatment of toe onychomycosis on a weekly regimen, turning out to be a more convenient posologic option and allowing for a better commitment to the treatment. $\square$

TABLE 7: Overall Results

\begin{tabular}{llll}
\hline Posologic Regimen & Mycologic Cure & Therapeutic Success & Clinical Improvement \\
\hline Once/week & $70 \%$ & $45 \%$ & $50 \%$ \\
$3 / 2 / 1$ & $71,43 \%$ & $42,86 \%$ & $52,38 \%$ \\
\hline
\end{tabular}

\section{REFERENCES}

1. Sociedade Brasileira de Dermatologia. Perfil nosológico das consultas dermatológicas no Brasil. An Bras Dermatol. 2006;81:549-58

2. Souza EAF, Almeida LMM, Guilhermetti E, Mota VA, Rossi RM, Svidzinski TIE. Freqüência de onicomicoses por leveduras em Maringá, Paraná, Brasil. An Bras Dermatol. 2007;82:151-6.

3. Araújo AJG, Bastos OMP, Souza MAJ, Oliveira JC. Ocorrência de onicomicose em pacientes atendidos em consultórios dermatológicos da cidade do Rio de Janeiro, Brasil. An Bras Dermatol. 2003;78:299-308.

4. Berker D. Clinical practice. Fungal Nail Disease. N Engl J Med. 2009;360:2108-16.

5. Welsh 0, Vera-Cabrera L, Welsh E. Onychomycosis. Clin Dermatol. 2010;28:151-9.

6. Porro AM, Yoshioka MCN. Manifestações dermatológicas da infecção pelo HIV. An Bras Dermatol. 2000;75:665-88.

7. Zaitz C, Campbell I, Marques S, Ruiz LRB, Souza VM. Compêndio de Micologia Médica. Rio de Janeiro: Medsi; 1998. p.81-98.

8. Bohn M, Kraemer KT. Dermatopharmacology of ciclopirox nail lacquer topical solution $8 \%$ in the treatment of onychomycosis. J Am Acad Dermatol. 2000;43(4 Suppl):S57-69.

9. Gupta AK, Fleckman P, Baran R. Ciclopirox nail lacquer topical solution $8 \%$ in the treatment of toenail onychomycosis. J Am Acad Dermatol. 2000;43(4 Suppl):S7080.

10. Walters KA, Flynn GL, Marvel JR. Physicochemical characterization of the human nail: solvent effects on the permeation of homologous alcohols. J Pharm Pharmacol. 1985;37:771-5.

11. Kobayashi Y, Miyamoto M, Sugibayashi K, Morimoto Y. Drug permeation through the three layers of the human nail plate. J Pharm Pharmacol. 1999; 51:271-8.
12. Zanardi D, Nunes DH, Pacheco AS, Tubone MQ, Souza Filho JJ. Avaliação dos métodos diagnósticos para onicomicose. An Bras Dermatol. 2008;83:119-24.

13. Rosenberg W F, Lachin J M. Randomization in Clinical Trials. New York: John Wiley \& Sons; 2002. p. 53

14. Chow S, Liu J. Design and analysis of clinical trials: concepts and methodologies New York: John Wiley \& Sons; 2005. p.120-66.

15. Baran R. Ciclopirox nail lacquer: the first prescription topical therapy for onychomycosis. J Am Acad Dermatol. 2000;43(4Suppl):S55-6.

16. Gontijo B, Zaitz C, Bartelle C, Azulay DR, Campbell I, Cestari S. Avaliação do ciclopirox no tratamento das onicomicoses. An Bras Dermatol. 1998;73:395-401.

17. Gupta AK, Baran R. Ciclopirox nail lacquer solution $8 \%$ in the 21 st century. J Am Acad Dermatol. 2000;43(4 Suppl):S96-102.

How to cite this article/Como citar este artigo: Schalka S, Nunes S, Gomes-Neto A. Comparative clinical evaluation of efficacy and safety of a formulation containing ciclopirox 8\%in the form of a therapeutic nail lacquer in two different posologies for the treatment of onychomycosis of the toes. An Bras Dermatol. 2012;87(1):19-25. 